\title{
CORRECTION
}

\section{Correction to: An Innovative Approach to Modelling the Optimal Treatment Sequence for Patients with Relapsing-Remitting Multiple Sclerosis: Implementation, Validation, and Impact of the Decision-Making Approach}

Marjanne A. Piena - Sonja Kroep - Claire Simons · Elisabeth Fenwick •

Gerard T. Harty $\cdot$ Schiffon L. Wong · Ben A. van Hout

Published online: January 8, 2022

(C) Springer Healthcare Ltd., part of Springer Nature 2022

Correction to: Adv Ther

https://doi.org/10.1007/s12325-021-01975-5

In the original article, Refs. 18 and 31 are the same reference but were published as different references.

The original article has been corrected.

The original article can be found online at https://doi. org/10.1007/s12325-021-01975-5.

M. A. Piena $\cdot$ S. Kroep

MMA, Evidence \& Access, OPEN Health, Rotterdam, Netherlands

C. Simons

MMA, Evidence \& Access, OPEN Health, York, UK

E. Fenwick

MMA, Evidence \& Access, OPEN Health, Oxford, UK

G. T. Harty ( $\square)$

The Healthcare Business of Merck KGaA, Frankfurter

Str. 250, 64293 Darmstadt, Germany

e-mail: Gerard.Harty@merckgroup.com

\section{S. L. Wong}

EMD Serono, Billerica, MA, USA

B. A. van Hout

School of Health and Related Research (ScHARR),

University of Sheffield, Sheffield, UK 